\title{
Una vida de organista: reflexiones en torno a Gerd Zacher
}

\author{
An organist's life. \\ Reflections on Gerd Zacher
}

\author{
por \\ Matthias Geuting \\ Robert-Schumann-Hochschule Düsseldorf, Alemania \\ matthias.geuting@rsh-duesseldorf.de
}

Una nota a modo de preámbulo ${ }^{1}$ : hace poco menos de cincuenta años, el 21 de marzo de 1970, el renombrado organista alemán Gerd Zacher interpretó en Hamburgo una nueva composición de Juan Allende-Blin de escasos quince minutos de duración: Mein blaues Klavier [Mi piano azul], una pieza para órgano y dos instrumentos adicionales, organillo y birimbao. El título de la obra lo adoptó el compositor de un poema homónimo de Else Lasker-Schüler, del que solo extrajo un verso que sirve de epígrafe a la obra: Zerbrochen ist die Klaviatür [quebrado está el teclado]. El maltrecho piano azul de juguete es un recuerdo imaginado de la infancia de la gran poeta judía. Expulsada en 1933 de la Alemania nazi, Else Lasker-Schüler describe poéticamente en estos versos su nostalgia por un tiempo irrecuperable, a la vez que su dolor ante un mundo embrutecido. ¿Puede la música expresar estas sensaciones? ¿Es la música capaz de expresar pensamientos? Quien conoce a Juan Allende-Blin sabe que él desde sus comienzos ha cultivado en su música un clima de duelo y de memoria. Es ese duelo proveniente de una añoranza y de una fragilidad lo que Allende-Blin expresa por medio de una estructura articulada con precisión. Su música respeta la substancia del poema, pero de una manera libre y asociativa.

El estreno de esta obra en Hamburgo constituyó un hito en la historia del órgano, porque era la primera obra que debía ser ejecutada con una constante reducción de la presión del aire que alimenta los tubos del instrumento. Así lo exige la partitura de Allende-Blin. La reducción del aire, por medio de un mecanismo especial, produce una gran fragilidad e inestabilidad de los sonidos que se descomponen en sus alícuotas, y que pueden ir disminuyendo hasta incluso desaparecer: "Un acorde tocado sforzato en el órgano con la presión reducida del aire, produce un efecto como si un suspiro sonoro se ahogara (sonoridad similar a la que se puede escuchar en pianos destemplados). En suma, todo suena como una cita de un antaño que evoca su propia lejanía” (Zacher 2014: 44). Esta obra que debe ejecutarse enteramente con la presión reducida del aire, se infla brevemente en la mitad de la pieza tratando en vano de recuperar el vigor perdido.

En el último tercio aparecen esbozados algunos fragmentos de la Sonata $n^{\circ} 3$ para piano en fa sostenido menor, op. 23, de Aleksandr Skrjabin y del Estudio en mi bemol menor op. $10 \mathrm{n}^{\circ} 6$ de Frédéric Chopin distorsionados por la presión reducida del aire-como recuerdos de otro tiempo en que el compositor los había tocado, fragmentos que se van desvaneciendo-. Cerca del final de Mein blaues Klavier se reconoce incluso una alusión a la Ópera de los tres centavos sumergida en las profundidades

1 El presente documento ha sido traducido del alemán por Alex Gibert.

Revista Musical Chilena, Año LXXV, enero-junio, 2021, No 235, pp. 217-227 Fecha de recepción: 09-07-2020. Fecha de aceptación: 22-09-2020 
del pedal: Bedenkt das Dunkel und die große Kälte [Pensad en la oscuridad y el intenso frío]. Pero esto no es todo. A los sonidos irreales que produce el órgano tratado con una presión baja del aire se agregan los sonidos fragmentados del organillo, pues el intérprete de este instrumento debe mover la manivela con movimientos entrecortados. El modo de tocar el organillo se estipula expresamente en la partitura: "Girar la manivela lenta y entrecortadamente, con largos silencios, sin periodicidad regular alguna. Detenerse en cuanto la melodía que el azar haya elegido pueda reconocerse”.

Para el estreno en Hamburgo de esta obra el pastor de la iglesia en la que tuvo lugar debió arrendar un organillo en Sankt Pauli, un barrio de mala fama. Años después, el pastor se reía irónicamente de este atrevido arriendo. Además del organillo, para el final de la obra, el organista debe tocar un tercer instrumento: un birimbao, cuyo sonido se genera en el ámbito bucal del organista, proyectando de una manera inquietante su propio aliento en el espacio de la iglesia. Simultáneamente produce el pedal un sonido tembloroso, casi un hálito.

Mein blaues Klavier se cuenta hoy entre las composiciones más conocidas de Allende-Blin². Después del estreno, Gerd Zacher se despidió de Hamburgo, donde se había iniciado su larga y exitosa carrera de concertista interrumpiéndola en su cumbre, para ocupar el puesto de profesor y director del Departamento de Música Sacra Evangélica de la Escuela Superior Folkwang de Essen. Zacher añade una capa interpretatoria a las ya expuestas al referirse al centro de la obra como un diálogo entre dos instrumentos diametralmente opuestos por su origen y su estatus musical: el órgano "rico" y el órgano "pobre". El rico es por supuesto el potente instrumento sacro, que aquí se enfrenta a su reflejo más humilde, el organillo u "órgano callejero" (el street organ inglés). En el estreno de la pieza, el compositor Juan Allende-Blin, compañero de vida y de profesión de Zacher durante muchos decenios, al parecer no quiso privarse del placer de tocar el organillo (como en tantas otras presentaciones posteriores). ¿Pretendía aludir con ello a la precaria situación vital y laboral de los compositores? Poco probable. Más bien se trataba de una crítica al origen y estatus social del propio órgano, que a pesar de ser uno de los instrumentos sonoros más antiguos y complejos que existen, ha estado expuesto desde sus inicios a los más diversos juicios y estereotipos y, en cierto modo, sigue pasando por una excentricidad.

El órgano ha basculado siempre entre ambos extremos. Por un lado, se idolatra y se arrincona en razón de sus mismas virtudes [...] y, por el otro, corre por las ferias programado mecánicamente para tocar canciones populares. A veces, ambas variantes intercambian sus roles: el son del organillo puede resultar sumamente grato, gracias a la transparente entonación de sus delicados tubos y a sus cilindros hábilmente perforados, con el ritmo calculado a la perfección; el órgano de iglesia, por el contrario, invita en ocasiones a principiantes y virtuosos por igual a lamentables ejercicios de mortal precisión, ya sean estos pretenciosos o apocados. El órgano ha sido desde el principio un instrumento de extremos. Y es justamente en este carácter radical donde reside su encanto (Esch y Schneider 2017: 7).

Para el intérprete y compositor Gerd Zacher, el "extremismo" del órgano fue un tema vital y una fuente inagotable de experiencia musical. El órgano, como él decía en una formulación muy suya, era su "banco de ensayos para analizar detalladamente cualquier fenómeno musical". Solo aquello que ha sido asimilado e interiorizado durante las largas y solitarias horas dedicadas al instrumento es digno de ofrecerse a un público receptivo.

La relación que Juan Allende-Blin y Gerd Zacher mantuvieron durante sesenta y dos años fue rica en influencias recíprocas y estuvo siempre íntimamente ligada al órgano. La actividad de Gerd Zacher como organista, así como la obra de Allende-Blin, consagrada en buena parte a este instrumento, no podrían entenderse sin conocer la historia más reciente de la música organística y los cambios radicales que experimentó a principios de la década de 1960. En aquellos años surgió en Europa (especialmente en Suecia, Alemania y Francia) y en Estados Unidos una nueva hornada de compositores dispuestos a tomarse en serio el órgano como instrumento de concierto y a compatibilizarlo con las distintas corrientes contemporáneas de pensamiento musical (un proceso que trajo consigo, de paso, innovaciones

2 Véase, entre las publicaciones más recientes, Esch y Schneider 2017, pp. 65-68. 
substanciales para el diseño y la construcción de órganos). Las novísimas composiciones para órgano de músicos de renombre -desvinculados por lo demás de la música sacra-surgidas a principios de los años sesenta a raíz de la iniciativa de una pequeña emisora de radio del norte de Alemania, causaron sensación. En Volumina, por citar el ejemplo más conocido, György Ligeti ponía en juego imponentes masas y paisajes sonoros, cuya interpretación no solo requería una notación musical particular, sino también una técnica desconocida hasta la fecha (entre otras cosas, incorporaba clusters cromáticos estáticos y móviles que había que tocar con las palmas de las manos o los antebrazos). La pieza de Ligeti delataba influencias de Bengt Hambræus, que ya en Constellations I, composición de 1958, hacía un uso completamente nuevo del órgano. En Interferenzen, obra algo posterior de Hambræus, las pulsaciones características del órgano, originadas en batidos de muy distinta naturaleza, se erigían en principios determinantes del sonido y de la forma.

En Improvisation ajoutée de Mauricio Kagel, obra que en un primer momento parece inscribirse en el marco de la música de órgano tradicional, el "verdadero" intérprete está flanqueado por dos ayudantes para los registros, cada uno muy atareado con su propia partitura. Poco a poco los ruidos y las emisiones verbales de los tres intérpretes van tomando protagonismo, mezclándose con la música del órgano en un espectáculo grotesco, amenazante incluso. La pieza de Kagel polarizó al público entendido como pocas lo habían logrado hasta la fecha. Tras una interpretación de la pieza a cargo de Zacher durante la Semana del Órgano de Núremberg de 1967, un párroco se quejaba en su sermón de que "en lugar de glorificar a Dios, se diría que esta música busca rebelarse contra Él. [...] Como si de pronto la música sacra se hubiera convertido en una música diabólica, rebasando con creces el límite de lo tolerable en el ámbito de la música sacra”" Un año antes, en la iglesia parisina de Saint Séverin y en presencia de Olivier Messiaen, Zacher había ejecutado aquella misma pieza con resultados igualmente escandalosos:

La manzana de la discordia en el concierto parisino fue Improvisation ajoutée de Kagel con la superposición de cuchicheos, cantos, aplausos, toses, risas y gritos del organista y de sus asistentes: los dos compositores Juan Allende-Blin y Giuseppe G. Englert. Messiaen se sentó en un rincón y estudió la partitura más de un cuarto de hora: 'Ca sonne comme une femme qui accouche' [suena como una parturienta] (Zacher s/f).

Por el contrario Dieter Schnebel, compositor y teólogo, apuntaba al respecto que esta música "revela el pavor apocalíptico que los hombres, en su espera, son capaces de producir. En ese sentido, el miedo que produce no es en absoluto profano" (Schnebel 1972: 302). Como recordaría más tarde el propio Zacher, "a principios de los sesenta aquella pieza impactó como un meteoro en la planicie de la música sacra alemana. [...] A mí me horrorizaba el horror que causaba a la gente, pero no podía ahorrárselo: las discrepancias han tenido siempre efectos muy positivos sobre mis interpretaciones" (Zacher 1991: 136).

Más allá de la polémica en torno a su recepción, aquellas composiciones singulares, escandalosas e intensas ejercieron como catalizador de la música de órgano entre los contemporáneos más sensibles, los que entendían que tarde o temprano no quedaría otra alternativa si se quería ahondar de verdad en el arte de la composición organística. Sea como fuere, las características particulares del instrumento resultaban muy propicias a las diversas tentativas de objetivación y racionalización llevadas a cabo por la música más transgresora de la época. El "descubrimiento" del órgano y, más concretamente, la exploración experimental de sus posibilidades sonoras conllevaba además grandes desafíos para los constructores de órganos, cuyas innovaciones se veían a su vez reflejadas en las creaciones musicales. En retrospectiva, hay que reconocer que la emancipación del instrumento sacro en los años sesenta se llevó a cabo a una velocidad vertiginosa (y muy propia de cualquier revolución, por otra parte). En poquísimo tiempo los pioneros sondearon el terreno de aquel nuevo arte prácticamente en su totalidad. Y en lo que respecta a la "exploración material", las obras fundamentales de aquellos años fueron de una importancia capital. La apuesta por un uso más creativo y amplio de aquel medio de expresión recién redescubierto estaba a la orden del día. 
En todo caso, la renovación musical del órgano no habría sido posible sin la colaboración de un grupo de intérpretes libres de prejuicios y dispuestos a reflexionar acerca de los fundamentos del instrumento y su potencial sonoro. El organista alemán Gerd Zacher fue uno de ellos ${ }^{4}$. Cuando descubrió y comenzó a trabajar la obra de Ligeti y Kagel, Zacher rondaba los cuarenta años y atesoraba ya un profundo conocimiento del repertorio organístico tradicional. Ávido de obras más modernas dignas de atención, estudió entonces varias piezas de órgano de principios y mediados del siglo XX, composiciones de cierta importancia que apenas se interpretaban en público, como las Variaciones sobre un recitativo de Arnold Schönberg y las sonatas de Darius Milhaud y Ernst Krenek. También estudió la ya entonces vasta obra organística de Olivier Messiaen, y muy especialmente su Livre d'orgue de 1951 que, a su juicio, abría perspectivas instrumentales radicalmente nuevas. Un caso singular fue el de otra obra que incorporó entonces a su repertorio, la Sonata para órgano del catalán Josep Maria Mestres Quadreny, compuesta en Barcelona en 1959 para un órgano de cinco manuales, que es uno de los escasos y notables ejemplos de música para órgano conforme con los estrictos principios seriales (véase Zacher 1968b; Philippi 2002: 109-115).

Pese a todo, los aquí enumerados ejemplos ilustres no desembocaron en un desarrollo realmente continuo, porque los más influyentes compositores vanguardistas del período postserial -y que trabajaban mayormente en un contexto laico-, no fueron fáciles de ganar para la causa de un instrumento con una carga de tradición tan abrumadora. Una eventual continuidad requeriría de la iniciativa individual de compositores que fueran capaces de llegar a conclusiones pertinentes a partir de un análisis personal y detallado de la coyuntura. A partir de los años sesenta ese individuo no fue otro que Gerd Zacher, que sobresalió siempre en su faceta de animador, promotor e intérprete de la nueva música organística, alentado por el compositor Juan Allende-Blin, otro gran entusiasta del órgano. Y despertó el interés de un público extraordinariamente amplio, que iba más allá de los medios especializados; hasta los periódicos y revistas más importantes de Alemania Occidental informaban entonces acerca de la labor de Zacher en la iglesia luterana de Wellingsbüttel en Hamburgo, algo que hoy podría parecer inverosímil ${ }^{5}$. Zacher estrenó allí numerosas piezas que hoy han pasado a formar parte del canon organístico y que le valieron la merecida etiqueta de "revolucionario del órgano"6. Para él componían figuras de la talla de Juan Allende-Blin, Hans Otte, Isang Yun, Giuseppe Englert, György Ligeti, Dieter Schnebel, Mauricio Kagel, Sylvano Bussotti y, más adelante, el mismísimo John Cage. La mera mención de los compositores más conocidos con los que colaboró compone un who is who del panorama internacional de la música contemporánea en la década de 1960. No es de extrañar que, en líneas generales, no fueran organistas sino músicos ajenos al órgano quienes abrieran nuevos horizontes para el instrumento. En este sentido, hay que destacar la importantísima aportación de Juan Allende-Blin, que guiaría e influiría en gran medida la trayectoria organística de Zacher y cuya familiaridad con el instrumento salta a la vista en todas sus partituras. Entre las primeras obras que Allende-Blin estrenó en Hamburgo merece una mención aparte su monumental pieza en tres movimientos Echelons, compuesta entre 1962 y 1967. El último movimiento de esta obra ("Sons brisés") es un estudio que analiza la respiración propia del órgano, en la que durante largas frases se va menguando la presión del aire al apagarse el motor, recurso determinante para la concepción formal de la pieza, en la que también se incluyen ruidos directamente ligados a la producción de los sonidos (Zacher 2002).

Como no podía ser de otra manera, la intensa dedicación de Zacher a las nuevas composiciones -así como las posibilidades que se le abrieron en Hamburgo tras la construcción de un nuevo órgano en cuyo diseño tomó parte- le estimuló a crear sus propias piezas, y antes de que acabara la década de 1960 ya había compuesto y estrenado cinco obras para órgano solo (además de otra para órgano y soprano). Se trata de composiciones difícilmente subsumibles bajo un denominador común, pues su composición responde a planteamientos muy diversos. Con todo, es característica la coherencia con la que Zacher escoge derroteros aún inexplorados o descuidados por la tradición. Lo nuevo, según la definición personal de Zacher, debe rastrearse en la historia olvidada, en las posibilidades pasadas por alto; la memoria y el descubrimiento deben entenderse, por tanto, como conceptos íntimamente

4 Es relevante destacar también, en este sentido, la fructífera colaboración entre el organista sueco Karl Erik Welin y György Ligeti.

5 Véase, por ejemplo, "Schrecken und Schauder, Der Spiegel, N 13 (1972), www.spiegel.de/spiegel/ print/d-42945091.html. [acceso: 18 de mayo, 2021].

6 Una visión muy completa se ofrece en Funtenberger 2020. 
relacionados. Un punto de partida de su concepción musical del órgano se encuentra en su obra Diferencias, de 1961: en la estela de Messiaen, este ciclo organístico de diez movimientos plantea su propia transformación de los principios seriales, gracias a su invención de los llamados intervalles-durées, un sistema que asigna a cada intervalo su propia duración fija (y va, pues, un paso más allá que los sons-durées de Messiaen). A finales de aquella década, en 1969, Zacher compondría otra pieza situada de alguna manera en el extremo opuesto: Ré, una obra para organista y afinador concebida sobre una serie de notas pedal en re, cuyo sonido se somete a sutiles modificaciones mediante la precisa intervención de otro intérprete, en el interior del órgano, que manipula los labios de los tubos y va cambiando la afinación de la lengüetería 7 .

$$
* * * *
$$

Es preciso señalar, sin embargo, que Gerd Zacher nunca quiso especializarse en la música estrictamente contemporánea. Era más bien la visión de conjunto lo que le interesaba. La confrontación de la música nueva con la antigua y la más antigua; el redescubrimiento de las sonatas de Felix Mendelssohn Bartholdy, menospreciadas durante tanto tiempo y suprimidas del canon a partir de 1933; la recuperación de joyas desconocidas como la Messe des Pauvres de Erik Satie: tales eran, entre otros, los propósitos de Zacher en su faceta de organista. La división general entre música "antigua” y música "nueva" no le parecía pertinente, sobre todo porque la radicalidad de lo nuevo, como él mismo había expresado ya en un artículo, "[encuentra] su sentido, primeramente, como descubrimiento de las propias raíces” (Zacher 1968a: 4). Partiendo de su experiencia musical contemporánea, Zacher detectaba en las grandes obras del pasado las corrientes "utópicas", por así llamarlas, que conferían a sus interpretaciones ese carácter vital, inconformista y distintivo, pero que emanaban siempre de un conocimiento musical profundo y no de la intuición ciega. Sus interpretaciones se distinguían porque sorteaban los acostumbrados estereotipos expresivos y proponían, en su lugar, un viaje sin compromiso y de extraordinaria voluptuosidad por medio de un enorme acopio de información musical, lo que a juicio de la crítica resultaba "a menudo en exposiciones casi radiológicas" del repertorio organístico (Metzger 2006a: 273). Junto con la exigencia de "llevar a la esfera auditiva todo lo que podía leerse en la partitura" (como apuntaría el propio Zacher con motivo de una interpretación del Arte de la Fuga de Bach), crecía en él la convicción de que la comprensión esencial de cualquier pieza musical -incluido su instrumental teórico constitutivo- podía extraerse de las propias notas. La habilidad de Zacher para leer una partitura "entre líneas" -especialmente en el caso de la música antigua- dependía sobre todo de cuestiones técnicas de digitación o de articulación que a su juicio podían resolverse de forma plausible a partir de la pieza en cuestión, y no tanto a base de los documentos históricos comúnmente invocados por los intérpretes del órgano (y de ningún modo, por cierto, mediante la mera e irreflexiva maestría instrumental).

Zacher le dio a uno de los textos programáticos fundamentales de su época en Hamburgo -escrito inicialmente para una revista musical francesa y aparecido más adelante en una publicación de música sacra de amplia difusión- un título harto elocuente: Werkzeug Orgel [órgano (como) herramienta] (Zacher 1968a). En él se posicionaba decididamente en favor de la revalorización del órgano como medio de expresión complejo y destinado exclusivamente a la producción sonora, más allá de su apropiación religiosa o ideológica. El artículo describía las principales innovaciones interpretativas de la época, que a su juicio no eran más que herramientas favorecedoras de una "multiplicación de la expresividad”. Una técnica pionera era la manipulación del suministro de viento del órgano, que abría metafóricamente una entrada a las tripas del instrumento, tras su fachada de apariencia inamovible, permitiendo ingresar a su compleja vida interior y su desconocido, frágil, aéreo y vital potencial sonoro. Resultaba, a la postre, que lo que tenía de nuevo la música contemporánea organística había estado allí desde siempre: la visión del órgano como instrumento de viento, dotado contra todo pronóstico del potencial necesario para satisfacer las exigencias y la visión de los compositores contemporáneos. Ligeti había hablado tiempo atrás de la "descomunal variedad de [...] colores sonoros por explorar" en el órgano, al tiempo que lamentaba las obvias deficiencias que exigía su empleo productivo como instrumento: "El órgano es comparable a una gigantesca prótesis. Me interesaba averiguar de qué

7 Cf. la grabación que Zacher lanzó en 2005 de sus obras para órgano compuestas entre 1961 y 1971 (Cybele SACD 060.501). 
manera esta prótesis nos pudiera ahora enseñar a andar" (Ligeti 2007: 186). La posibilidad de manipular el suministro de aire de los tubos era viable desde el teclado y de los registros mecánicos (en los órganos mecánicos), pero también por medio de los fuelles (encendiendo y apagando el motor). De cuando en cuando aparecían nuevas e imaginativas soluciones técnicas: en 1966, para el estreno del Estudio $n^{\circ} 1$ de Ligeti ("Harmonie"), Zacher hizo incorporar al órgano un pequeño motor de aspiradora para generar un suministro de aire atenuado de forma constante, pues Ligeti desea "colores sonoros extremadamente delicados, mortecinos y aéreos, singularmente distorsionados".

Los responsables de tan esencial revolución para el órgano tenían bien claro que habría que lidiar con agresivas reacciones en su contra y que en cualquier momento podría desencadenarse lo que hoy recibiría en inglés el nombre de shit storm, pues era evidente que se proponían liberar el instrumento de la estrechez de miras de la música sacra y ganarlo (o recuperarlo) para el arte moderno, lo que les valdría el anatema de los círculos partidarios de la restauración del órgano tradicional. Semejante empresa no podía gustar a todo el mundo, claro está, y disgustaba especialmente a aquellos que, consciente o inconscientemente, seguían inmersos en las tesis de una ideología cultural nazi a la que aún le quedaba mecha. Más de una vez, como rememoraría Zacher más tarde, los carteles de sus conciertos en el Conservatorio de Hamburgo fueron retirados por los propios responsables de la institución. Baste aquí citar, como botón de muestra, una carta que le envió Otto Brodde, intérprete de música sacra y profesor del conservatorio muy influyente a la sazón: "Lo que usted denomina 'música' no nos parece más que una acumulación de estridencias. [...] Es evidente que quien acude a la iglesia para escuchar música no ha venido en busca de experimentos acústicos. [...] Sus ideas sobre el 'órgano [como] herramienta' me parecen un desatino, un disparate del que es preciso tomar buena nota, aunque no quepa discutir de ello por pura falta de fundamento"8. Para plantar cara a las tendencias reaccionarias de la música sacra evangélica "oficial" hacía falta cierta disposición estoica y una buena dosis de determinación inconformista.

Nacido en 1929, Zacher pertenecía a una generación marcada muy especialmente por el cataclismo histórico de 1945. Cuando tenía siete años, su abuelo le tocaba al órgano ciertos movimientos de las sonatas de Félix Mendelssohn-Bartholdy. Lo hacía a escondidas, porque Mendelssohn era un compositor prohibido desde 1933. Aquella experiencia temprana se asentaría profundamente en la memoria del niño, cristalizando en la convicción de que "con prohibiciones no puede practicarse ninguna clase de arte”, como él decía. Especialmente fructífero resultaría, años más tarde, el encuentro entre Zacher y el joven compositor Juan Allende-Blin, que había llegado a Alemania desde Chile a principios de los años cincuenta para cursar estudios en la Academia Superior de Música de Detmold. Zacher y Allende-Blin coincidieron en la clase de composición de Günter Bialas y allí nació entre ellos el aprecio y el amor que los haría inseparables durante más de seis decenios (hasta la muerte de Zacher en 2014). La relación afectiva y profesional de intérprete y compositor fue sin lugar a duda, y en más de un sentido, un golpe de suerte: muy difícilmente habría llegado ninguno de los dos a ser quien fue en ausencia del otro. Podría decirse que por medio de Allende-Blin se le abrieron precozmente a Zacher las puertas a un riquísimo fondo de relaciones humanistas y formativas que cada uno de los dos supo integrar de modo fructífero en su sistema de pensamiento asociativo.

En retrospectiva, la mudanza en común a Santiago de Chile, ciudad natal de Allende-Blin, también fue algo más que un episodio en la biografía artística de Zacher. Allí, en 1954, Zacher encontró trabajo como director de coro y organista de la Iglesia Evangélica Luterana de la calle Lota; allí, a sus veinticinco años, comenzó a atesorar una experiencia valiosísima como organista, director de coro, pianista y clavecinista, que cimentó las bases de su carrera interpretativa. La escasez y relativa sencillez de los instrumentos disponibles en Santiago y sus alrededores había limitado su repertorio organístico a piezas de cierta antigüedad. "Su" instrumento era un órgano de dos manuales de la casa Walcker, fabricado en la década de 1930 y dotado de una veintena de registros (una de numerosas importaciones llegadas a partir de 1860 desde Alemania), que se encontraba entonces en un estado lamentable y que hoy aún sigue en pie, habiendo sido sometido a toda clase de reconstrucciones. A tono con el

8 Otto Brodde, carta a Gerd Zacher fechada el 19 de octubre de 1968 (archivo de la Akademie der Künste de Berlín). 
instrumento, el repertorio que tocaba entonces Zacher se ceñía a la música de los siglos XVII, XVIII y XIX y muy especialmente a la música organística de Johann Sebastian Bach, que en aquellos años el intérprete se dedicó a explorar de forma más o menos sistemática. Los conciertos periódicos de órgano de la iglesia evangélica se convirtieron en aquellos años en una verdadera institución. Como es natural, Zacher también se interesó por otros órganos de su entorno: buen ejemplo de ello fue el "Recital académico de órgano" que dio en el Aula Magna de la Escuela de Derecho de la Universidad Católica de Valparaíso. Paralelamente a su labor como intérprete solista, Zacher creó un coro y un conjunto de música antigua. Como director del coro, acercó al público composiciones de Heinrich Schütz, Dieterich Buxtehude y Georg Philipp Telemann, entre otros; los grandes éxitos que cosechó con el coro incluyeron una función concertante de Dido y Eneas de Henry Purcell que dio en 1955 en el Instituto Chileno-Británico de Cultura y un festival dedicado a la música de Schütz en el Instituto Chileno-Alemán de Cultura.

A juzgar por la actividad que Zacher llevó a cabo en Chile como organista y adalid de la música sacra, podría parecer sorprendente que al poco tiempo, de vuelta en Alemania, se convirtiera en uno de los pioneros de la música contemporánea organística. No hay que olvidar, sin embargo, sus aspiraciones pianísticas, a las que dio rienda suelta en sus años chilenos. En la Asociación Nacional de Compositores tocó, por mentar solo unos pocos ejemplos, la Sonata ${ }^{\circ}$ 10, op. 70, de Skrjabin, así como los visionarios Quatre études de rythme de Messiaen; y en la Universidad Católica presentó una pieza pianística propia, titulada Fünf Transformationen [Cinco transformaciones], título que tomó prestado a Allende-Blin, que había comenzado poco antes una serie con el mismo nombre. En aquella pieza -como en casi todas sus tentativas tempranas de composición, por lo demás- Zacher se situaba en la estela de Messiaen y andaba ya en busca de un sistema propio de composición serial, sobre todo respecto del ritmo y a la configuración del tempo, propósito que en composiciones posteriores seguiría desarrollando y concretizando. Así pues, no era tan difícil reconocer ya entonces el asombroso potencial del joven músico, que superaba con creces los recursos habituales de un pianista y organista con aspiraciones.

$$
* * *
$$

De vuelta de Chile, inaugurando una nueva etapa biográfica como director del coro y organista de la Iglesia Luterana de Hamburgo-Wellingsbüttel, puesto que ocupó en 1957, Zacher comenzó a desarrollar una noción de la interpretación caracterizada por su amplitud de miras, despertando así la curiosidad de un público alemán e internacional cada vez más nutrido. El cometido del intérprete, según su nueva concepción, iba más allá de la tríada convencional de estudio, práctica y ejecución musical, y debía abarcar un contexto mucho mayor (Zacher 2006). Su labor comenzaba, naturalmente, con la elección de las piezas de acuerdo con los instrumentos disponibles y la concepción de un programa con fundamento que, en cierto modo, también era preciso "componer". Podía comprender asimismo propuestas y presentaciones de nuevas obras para el instrumento en cuestión, con objeto de ampliar o corregir la propia concepción de este. La interpretación comprendía también, si era posible, la estrecha colaboración con excelentes compositores de los más diversos estilos. Y, por descontado, entrañaba una multitud de iniciativas que, más allá del propósito común del concierto, buscaban entablar y desarrollar el contacto con los oyentes. La convicción de Zacher a este respecto era clara: en principio, todo lo que el intérprete de una pieza compleja está en condiciones de oír puede ser también transportado al público durante su ejecución. Para ello se debe recurrir y ejecutar todos los medios que sean necesarios. Una praxis musical de esta clase no era empresa fácil y exigía el coraje de todas las partes implicadas. "Cuando le doy a mi público lo que él desea, este recibe menos de lo que le puedo dar". Esta frase la repetía a menudo. Cada uno de sus programas de concierto eran inquietantes, pero durante su larga carrera, sus atentos auditores fueron comprendiendo sus intenciones con perspicacia creciente. De la seriedad con la que Zacher estimaba al público dan fe sus "Clases magistrales para oyentes": un formato de clase que concibió como acercamiento lúdico y expresivo a la música y que Zacher, siempre activo, ofreció hasta el final de su vida.

Su concepto de la interpretación se presenta de una manera ejemplar al realizar desde el órgano las Variations I for any kind and number of instruments de John Cage, porque en esta obra las fronteras entre composición e interpretación vistas por la personalidad de Zacher tienden específicamente a diluirse. Esta obra intrínsecamente abierta invita a un intérprete responsable, como lo es Gerd Zacher, a convertirse en coautor. Así encontró él la solución ideal. La vaguedad compuesta por Cage y que él llama indeterminación (indeterminacy) encuentra su correlación en la sutileza de la presión del dedo 
sobre la tecla para obtener una escala diferenciada de intensidades sonoras, a sabiendas de que es difícil de precisar el grado de sutileza necesario, corriendo el riesgo del fracaso. La operación comenzaba con una presión levísima de la tecla, que abría la válvula del tubo correspondiente produciendo así solo un suspiro de sonido; al aumentar poco a poco la presión de la tecla se aumenta gradualmente su intensidad hasta obtener la presión normal de la tecla produciendo entonces la intensidad máxima. "Era -decía Zacher- como si tuviera mis nervios ligados a los cables del órgano. Así cada movimiento del dedo controlado por el oído, cada fracción de un milímetro se convierte en expresión sonora. Cage se entusiasmó con este resultado, porque ningún detalle aquí es previsible: la interpretación misma se convierte en chance operation" (Zacher 2006).

La imposibilidad de controlar el resultado acústico, que podría haberse considerado como la debilidad de esta solución, fue de hecho acogida positivamente, pues aumentaba la carga de "impredecibilidad" que Cage buscaba en ejecución musical. El ejemplo también arroja luz acerca del nuevo ideal de interpretación que se estaba forjando, donde el intérprete capta las energías composicionales de una creación original y las transforma a la hora de ejecutarla en escena. "De no ser por Cage, jamás habría asumido semejantes riesgos", reconocía Zacher en referencia a uno de sus conciertos. En el mejor de los casos, también esta es una lección de Cage, la práctica de interpretar música se fundamenta en un conocimiento profundo de la composición. Al revés: el compositor comprende mejor su propia obra practicando la interpretación. La interpretación y la composición, ámbitos fundamentales del hecho musical, eran actividades indisociables para el organista-compositor Zacher, que vio siempre en ellas las dos caras de una misma moneda. Los "problemas de la interpretación", como había escrito Theodor W. Adorno, "[son], en un sentido estricto y espiritual, los de la composición” (Adorno 2005: 168). En ambos casos la pregunta primordial es la misma: ¿qué puede y debe hacerse audible?

La obra más famosa de Zacher, en la que su concepción de la interpretación es aún más audaz, es la célebre Kunst einer Fuge (El Arte de una Fuga) realizada entre 1968 y 1969 y dedicada a Theodor W. Adorno. Este ciclo se compone de "10 interpretaciones" -este es el subtítulo-, "del Contrapunctus I del Arte de la Fuga” en las que Zacher explora casi sistemáticamente las posibilidades de ejecución disponibles para un músico ${ }^{9}$. Naturalmente, el proyecto indaga en el carácter inconfundible y singular de la fuga; pero procede también de un modo absolutamente autorreferencial que podría considerarse como un ensayo acerca de los fundamentos de la interpretación musical. Y proclama a su vez un "arte de la audición": cuando Zacher toca la misma pieza diez veces seguidas, llenando con ellos un concierto completo, esto se conecta con una invitación al público a mantener activa y flexible su percepción de la composición histórica. Cada nueva realización sonora de la fuga exige una forma específica de audición, que busca hacer justicia a la complejidad intrínseca de la música mediante el cambio constante de perspectiva y cuestiona a su vez, lo adecuado o inadecuado de nuestras formas de escuchar, en el sentido ya prescrito por Theodor W. Adorno (a quien la pieza está dedicada), quien señala que "las obras son fenómenos objetivamente estructurados y dotados de sentido en sí mismos, que se prestan al análisis y que pueden percibirse y experimentarse en diversos grados de exactitud" (Adorno 1982: 180) ${ }^{10}$.

En principio, Zacher respeta la partitura de Bach en todas sus interpretaciones, pero cada una de las diez explora distintos aspectos melódicos, armónicos o rítmicos de la fuga. No es de extrañar, siendo así, que la experiencia del organista en la interpretación de la música propia de su época haya tenido incidencia en el proyecto. Los títulos y dedicatorias de cada una de las interpretaciones de la fuga remiten a puntos de encuentro con otros compositores: Robert Schumann y Johannes Brahms, para seguir con György Ligeti, Olivier Messiaen, Bengt Hambræus, Mauricio Kagel, Edgar Varèse, Juan Allende-Blin y Dieter Schnebel. Y en sus sutiles alusiones, la práctica interpretativa se inscribe en la órbita creativa del compositor citado en cada caso. Por aducir solo un ejemplo: en la cuarta variación

9 Cf. la grabación completa realizada en la iglesia evangélica de Essen-Rellinghausen: Die Kunst einer Fuge: Johann Sebastian Bachs Contrapunctus I in zehn Interpretationen, Mainz 1990 (Wergo WER 6184 2).

10 Según el amable testimonio de Juan Allende-Blin, durante el proyecto de las interpretaciones Zacher encontraba particularmente estimulante este escrito aparecido en 1968, en el que Adorno pone de relieve las "clases de comportamiento musical" durante el proceso de audición. 
(dedicada a Ligeti) el movimiento polifónico se recubre de tonos mantenidos mediante una suerte de "eco artificial"11, que desde la distancia evoca los paisajes sonoros de Ligeti en aquellos años. Los complejos acordes, que a decir de Zacher procedían de obras como el Concierto para violín de Alban Berg, abren otro espacio semántico para la música y confieren a la experiencia auditiva cierta oscilación entre uno y otro plano histórico. La concepción de la quinta variación (dedicada a Messiaen y titulada "timbres-durées") es deudora de ciertos procedimientos empleados en el Livre d'orgue (1951), por ejemplo, cuando las distintas duraciones de cada tono conservan su propio registro característico, haciendo audibles las diferentes duraciones por medio de colores sonoros característicos. En la séptima variación, la voz del organista que se añade a la música (como en la Improvisation ajoutée de Kagel) contribuye a subrayar la expresividad de los momentos cromáticos. La novena variación fomenta asimismo una forma de audición más plástica, pues al comienzo de cada interludio se apaga el motor del órgano y el sonido va menguando; procedimiento que ya antes había empleado constructivamente Allende-Blin en su pieza para órgano Sons brisés (1968) y que aquí se utiliza para subrayar una prolongada ausencia del tema de la fuga. Zacher emplea una metáfora audaz al comparar la función del fuelle con "un reloj de arena que va midiendo el transcurso del tiempo". En la interpretación dedicada a Schumann, la segunda de este ciclo, se perciben las proporciones de la fuga en un largo crescendo apoyado por el tiempo que huye (como sucede en las fugas $n^{\circ} 1$ y $^{\circ} 6$ del ciclo op. 60 de Schumann: Seis Fugas sobre B-A-C-H).

En relación con la tendencia claramente legítima, si bien estricta, de la llamada interpretación históricamente informada, el Arte de una fuga no pretende suprimir el impacto histórico de la pieza, ni las características que proyectan esta música hacia el futuro. Más bien se presenta como una generalización obligada. Acerca de este delicado equilibrio se pronunciaba el propio Zacher en estos términos:

Si exijo del oyente un conocimiento histórico previo, reduzco su capacidad de percepción. Si esa percepción es amplia y flexible, no obstante, cabe esperar que encuentre también en su propio horizonte alguna correspondencia histórica. Es obvio que la historia debe servir en todo momento como orientación para el presente. De aquello que quiero conseguir en el presente depende, empero, el modo en que percibo y valoro la historia. Los siglos que median entre Bach y nosotros no pueden negarse. De hacerlo, estaríamos rechazando también la orientación que la música de Bach puede proporcionarnos hoy (Zacher 1984: 410).

Las variaciones primera y última del Arte de una fuga de Zacher son, por razones distintas, un caso aparte. La primera, tocada como un cuarteto - es decir, simultáneamente en los tres teclados y el pedal-, y dedicada al propio Johann Sebastian Bach, parte hasta cierto punto de lo conocido, que era "lo adecuado", según Zacher: "El oyente identifica lo conocido, pero se le brinda también la oportunidad de constatar lo nuevo sin restricciones". Como no podía ser de otra manera, la última variación, titulada "(No-) Music", es diametralmente opuesta, en la medida en que pone punto final a un viaje que parte de lo conocido y se adentra en lo desconocido. Esta última interpretación "surge de los silencios de las pausas poco antes del final de la fuga” (véase Lüdtke 2005). El intérprete abandona entonces la tribuna del órgano y presenta la fuga a ojos del público en su versión "muda", es decir, en una transposición exclusivamente visual y corporal que se despliega en estilizados movimientos de director de orquesta. De este modo, la última interpretación va más allá del sonido, posibilitando una audición interna de la fuga en el recuerdo. La dedicatoria a Dieter Schnebel remite aquí a su obra de 1960 Nostalgie, un "solo para director de orquesta" que el propio Zacher llevó a escena repetidas veces en los años sesenta.

Asentado en la frontera entre la interpretación y la composición, el Arte de una fuga de Zacher apuesta por un enfoque multifacético de la comprensión de la obra que se encuentra en la médula de su estética de la interpretación y que más tarde replicaría en otros proyectos de características similares. ${ }^{12}$

11 Aquí y en lo sucesivo, la cita procede del programa del estreno, impreso en el folleto de la grabación de CD mencionada en la nota 9, que también se reproduce en una publicación posterior: Lüdtke 2005.

12 Como el proyecto de los años ochenta Hörperspektiven auf die Passacaglia, en el que se podían escuchar y comparar tres versiones de la Passacaglia en do menor BWM 582 de Bach. Cuando se escucha la Passacaglia interpretada por Zacher tres veces consecutivas “con los oídos de César Franck, Maurice 
La mera idea de presentar consecutivamente, en un lugar y un momento dados y, por así decirlo, en pie de igualdad, varias versiones de una misma pieza, no de forma arbitraria sino mediante criterios objetivables y vinculados al texto musical, pareciera oponerse a la intuición de la práctica musical: ¿acaso no busca todo intérprete la interpretación "correcta” de una pieza, la adecuada e imperativa en un momento dado, que no permite la comparación con ninguna otra? Asimismo, como dijo Hermann Danuser, es cierto que "la estructura de una obra musical que aparece en la partitura presenta un sinnúmero de vínculos que en su conjunto no pueden expresarse estéticamente mediante una única y 'correcta' instancia de producción sonora" (Danuser 1996: 1055). De acuerdo con esta concepción, el Arte de una fuga extrae, mediante el despliegue sucesivo de perspectivas dispares de la obra, la única consecuencia lógica. Se erige así, en palabras de Heinz-Klaus Metzger, en "modelo de multiplicidad de lo estrictamente correcto" (Metzger 2006b: 347). Pues por mucho que las diez versiones de la fuga diverjan enormemente en su patrón sonoro, todas ellas pueden merecer el título de "interpretación correcta, lograda y adecuada". Incluso se podría pensar en muchas otras interpretaciones, que aludan a otras facetas de la fuga. Una buena pieza musical, como nos muestra el intérprete Gerd Zacher, abre espacios de interpretación de una amplitud inesperadamente grande, si no ilimitada.

\section{BIBLIOGRAFÍA}

Adorno, TheOdor W.

1982 "Einleitung in die Musiksoziologie", Theodor Adorno, Gesammelte Schriften, Rolf Tiedemann (editor), vol. 14, Frankfurt a. M.: Suhrkamp.

2005 Zu einer Theorie der musikalischen Reproduktion, Henri Lonitz (editor), Frankfurt a. M.: Suhrkamp.

DANUSER, HERMANN

1996 "Interpretation", Die Musik in Geschichte und Gegenwart, parte temática, tomo 4, Kassel: Bärenreiter, col. 1055 .

Esch, Christian y Frank Schneider (Eds.)

2017 Immer auch ein politischer Impuls. Christian Esch und Frank Schneider im Gespräch mit Juan AllendeBlin, Altenburg: Kamprad.

Funtenberger, Verena (ED.)

2020 Gerd Zacher. Interpret und Komponist. Verzeichnis der Interpretationen, Werke und Texte, Brühl.

Geuting, Matthias (Ed.)

2006 Horizonte des Hörens. Gerd Zacher, Saarbrücken: Pfau.

LIGETI, GYÖRGY

2007 "Bemerkungen zu Volumina" [1966], Gesammelte Schriften, Monika Lichtenfeld (editora), vol. 2, Mainz: Schott, pp. 186-189.

LÜDTKE, JoACHIM (ED.)

2005 Bach und die Nachwelt, vol. 4, 1950-2000, Laaber: Laaber-Verlag, pp. 111-119.

Metzger, Heinz-Kiaus

2006a "Einige Gründe für die Notwendigkeit Gerd Zachers", Horizonte des Hörens. Gerd Zacher. Matthias Geuting (editor). Saarbrücken: Pfau, pp. 272-273.

2006b "Multiplizität des streng Richtigen”, Horizonte des Hörens. Gerd Zacher. Matthias Geuting (editor). Saarbrücken: Pfau, pp. 347-348.

Ravel y Arnold Schönberg”, la experiencia del intérprete con la música posterior a Bach se proyecta de nuevo, retrospectivamente, sobre su música; una tentativa de "oír con oídos ajenos", contra la propia costumbre, para descubrir tal vez algo nuevo en la composición histórica. Véase Gerd Zacher, texto de acompañamiento al programa de Hörperspektiven auf die Passacaglia, manuscrito sin fecha (archivo de la Akademie der Künste de Berlín). 
Philippi, DANiEla

2002 Neue Orgelmusik. Werke und Kompositionstechniken von der Avantgarde bis zur pluralistischen Moderne. Kassel: Bärenreiter.

SCHNEBEL, Dieter

1972 "Bericht von neuer Orgelmusik", Dieter Schnebel. Denkbare Musik. Schriften 1952-1972. Hans Rudolf Zeller (editor). Colonia: DuMont, pp. 294-302.

Stadtbibliothek Essen (ED.)

2020 Verzeichnis der Interpretationen, Werke und Texte. Verena Funtenberger (compiladora). Brühl: Edition Gravis.

ZACHER, GERD

1968a "Werkzeug Orgel", Der Kirchenmusiker 19, No. 5, pp. 1-4.

1968b "Zur Orgelmusik seit 1960”, Orgel und Orgelmusik heute. Versuch einer Analyse. Bericht über das erste Colloquium der Walcker-Stiftung für orgelwissenschaftliche Forschung 25.-27. Januar 1968. Hans Heinrich Eggebrecht (ed.), Stuttgart: Musikwissenschaftliche Verlags-Gesellschaft, pp. $86-95$.

1984 "Orgelmusik vor 20, 30 Jahren, als unsere Gegenwart noch Zukunft war", Acta organologica 17, pp. 406-415.

1991 "Meine Erfahrungen mit der Improvisation ajoutée", Kagel ... /1991. Werner Klüppelholz (editor). Colonia: DuMont, pp. 136-154.

2002 "Die atmende Orgel. Über Sons brisés von Juan Allende-Blin", Juan Allende-Blin. Ein Leben aus Erinnerung und Utopie. Stefan Fricke y Werner Klüppelholz (editores). Saarbrücken: Pfau, pp. 242-267.

2006 "Komponist, Interpret, Kommissionär”, Horizonte des Hörens. Gerd Zacher. Matthias Geuting (editor). Saarbrücken: Pfau, pp. 19-29.

2014 "Dialog zwischen Orgel und Leierkasten. Mein blaues Klavier' von Juan Allende-Blin", MusikTexte. Zeitschrift für neue Musik, 142, pp. 44-46.

s/f "Hörperspektiven auf die Passacaglia", manuscrito sin fecha, Archivo Akademie der Künste, Berlín. 